\title{
5
}

\section{Getting Started with Faculty Development}

\author{
Nadia Cordero de Figueroa and \\ Pedro A. Sandín-Fremaint \\ University of Puerto Rico, Río Piedras
}

As a result of an academic senate decision to reconceptualize the baccalaureate, the Río Piedras Campus of the University of Puerto Rico began, in late 1994, a major transformational process that has led it to rethink itself as a community of learners. One of the principal instruments of change has been our Center for Academic Excellence, created in early 1998 as a result of the transformational process. This chapter discusses the process that led to the creation of the center, as well as its structure, activities, and vision for the future. We bope that our experience will be useful to those institutions thinking about venturing into the area of faculty development.

\section{INTRODUCTION}

\begin{abstract}
A lthough many of our decisions turn out to be relatively inconseAquential, some of them are truly fateful. Such was the case with the University of Puerto Rico's Río Piedras Campus when its academic senate made the decision, in late 1994, to reconceptualize the total curricular structure of the baccalaureate. This decision, made in response to a proposal presented by the College of General Studies-the academic unit in charge of most of the general education component on the Rio Piedras Campus-that the senate examine a revision of this college's mission, has led to a rather penetrating process of reconsideration of much more than the undergraduate curricula. Among other consequences, it has led to a fresh interest in the teaching-learning processes as perhaps the very soul of curricula.
\end{abstract}


In this chapter, we would like to share with our readers the Rio Piedras Campus's experience getting started with faculty development. Although there had been in the past isolated efforts to provide support for faculty in the area of the teaching-learning processes, it was only in early 1998 that this concern became a line item in the campus's budget, with the creation of our center for Academic Excellence. In what follows, we will recount some of the steps taken-and some of the lessons learned-in designing, creating, and developing our Center for Academic Excellence.

\section{Setring the Context}

In 1995, just months after the academic senate's decision to reconceptualize the baccalaureate, the Rio Piedras Campus was accepted to participate in the American Council on Education (ACE)/Kellogg Project on Leadership and Institutional Transformation. The project committee soon decided to support the reconceptualization process by focusing on several work areas that would supplement the senate committee's work redesigning undergraduate curricula. One of these areas concerned teaching-learning processes, including research.

The task force in charge of this area soon began to conceive of institutional strategies that would promote better teaching-learning practices. Through a process of research and discussion, the task force began to envision the Rio Piedras Campus as a community of learners, and this concept, in turn, triggered new visions and understandings of teaching-learning processes. As a result, the task force began to work on a policy document that would offer concrete recommendations for this area of institutional concern. The document, titled Towards a Community of Learners: Reflections and Recommendations on the Teaching-Learning Processes at the Río Piedras Campus, was officially adopted as policy by the chancellor and the dean for academic affairs in 1999.

One of the recommendations made in this document was precisely the creation of a center that would support faculty in developing teaching skills, incorporating modern technology into their practice, and conducting action research in their classrooms, among other activities that enhance faculty development and the teaching-learning process. By the time the document was adopted as policy, however, our Center for Academic Excellence had already been created. Taking advantage of a window of opportunity made available by the concurrence of both the chancellor and the academic dean, we requested funds from the campus's 
Summer Initiatives Program and spent the summer of 1997 writing a proposal for the creation of the center.

\section{Envisioning the Center}

Departing from several readings around the concept of a learning-centered institution (Barr \& Tagg, 1995; Bonwell \& Eison, 1991; Boyer, 1990; Farmer \& Mech, 1992; Gabelnick, MacGregor, Matthews, \& Smith, 1990; Grunert, 1997; Meyers \& Jones; 1993, Silberman, 1996; Sutherland \& Bonwell, 1996), we set out to explore, both virtually as well as in real time and space, how other institutions had organized in order to attend to the development needs of their faculty. Devorah Lieberman, Director of the Center for Academic Excellence at Portland State University (PSU), whom we had met in the course of our participation in the ACE/Kellogg Project, suggested that we use the Professional and Organizational Development Network in Higher Education (POD) directory as a source for contact information of people involved in faculty development. Thus, we started to write these people requesting information on the way they have organized in order to pursue their goals. Many responded with helpful information and materials while others referred us to their web pages.

Meanwhile, we accepted an invitation to visit the Center for Academic Excellence at Portland State University. This trip turned out to be extremely important for our purposes. The visit was masterfully designed to give us a live understanding of their center's operation and of the ways in which it relates to short- and long-term institutional goals. One of the most valuable aspects of this visit, as we went from one meeting to another shadowing Dr. Lieberman and other members of their staff, was to discover how people at PSU are using a common lexicon in speaking about their work and their institution. "Scholarship of teaching" was an expression that surfaced many times, along with the concept of developing a culture of evidence based on continuous assessment. This observation helped us to understand that the creation of a truly dynamic faculty development center needs to be rooted in a process of cultural change. The center, in turn, must conscientiously reflect the values of this new culture which are what ultimately give it a vision. To graft a new faculty development center onto business as usual would not have a significant impact.

Apart from Portland, we visited the then recently established center at the Mayagüez Campus of the University of Puerto Rico and the centers of 
two universities in Michigan: the University of Michigan, Ann Arbor and Eastern Michigan University. These last two were recommended by Dr. Lieberman as very different examples (in terms of size, budget, and structure) of successful faculty development efforts. We must confess that we were struck by the hospitality and helpfulness of each and every faculty developer that we approached both personally and through the Internet.

Dr. Lieberman also suggested that if we could only attend one professional conference per year that it be the POD conference. We have been to POD conferences for the past three years and must say they are perfect for faculty developers. As new practitioners, we attended their preconference workshop for beginners and found it to be both informative and stimulating (Brinko \& Menges, 1997; Wadsworth, 1988). Attending POD's annual conferences are the best way to make sure that your new center is on the right track and on a par, at least in terms of vision and good ideas, with much more experienced ventures.

With all this input, and taking very carefully into account the peculiarities of our own institution, we sat down and developed our proposal which we presented to the task force in charge of developing the policy document on the community of learners and, eventually, to both the chancellor and the dean for academic affairs. The center we envisioned for the Rio Piedras Campus was conceived in light of the values espoused by this document and in view of the anticipated curricular changes that should emerge from the academic senate's process of reconceptualizing the baccalaureate. Thus, it would develop work in the following areas: 1) teaching-learning, including technology, 2) assessment and action research, and 3) service-learning. As of this writing, due mostly to budgetary constraints, most of our work has been in the first area, although we have made some ventures into the second one.

One of our concerns was finding a way of giving the center a measure of autonomy from the administration while, at the same time, making sure that it had the administration's support. Thus, it was decided that the center would be under the sponsorship of the deanship for academic affairs, but would be overseen by an advisory board made up of well-regarded faculty from the different colleges, of which the dean for academic affairs would be a member.

Although our center was officially created in January 1998, it was not until a year later that we were assigned facilities that would enable us to move from being only a virtual endeavor. Meanwhile, there was a shift in key positions on our campus: Both the chancellor and the dean for aca- 
demic affairs changed. This meant that we would need to expend much of our energy simply making sure that the new chancellor and dean would be brought into the loop. Actually, a change in such important positions would have normally entailed the end of our project. Under the ACE/Kellogg Project, however, the development of the change agenda had been entrusted basically to faculty. Thus, there was a grassroots investment in the project by members of the academic community. And this investment gave a certain weight and prestige to our initiative. Thus, in January 1999, notwithstanding yet another change in the chancellorship, the Center for Academic Excellence was officially inaugurated, ten months before the policy that recommended its creation was actually approved! Perseverance is indeed a virtue.

Our center is staffed by a part-time director, a part-time associate director, five part-time resident professors, a full-time secretary, a research assistant (assigned by the dean for graduate studies and research), and a work-study undergraduate assistant. We are housed in temporary quarters which, although small, have been furnished in a pleasing and welcoming manner. We have a reception area, two small offices, a meeting room, and a very small storage area where we keep materials, our photocopier, and an old refrigerator (essential for storage of refreshments served at meetings!). We also oversee a computer lab for faculty, whose operations are coordinated by a full-time nontenure-track professor.

\section{What We Have Accomplished}

The very first type of activity we developed was a series of workshops offered on Friday mornings or afternoons, which we called Viernes Didácticos (Pedagogical Fridays). Between six and eight of these workshops are offered each term on a wide variety of subjects, most of which are suggested by participants. Although we do use many professors from the College of Education for these workshops recruiting faculty from all of the other colleges. We do not want to give the impression that one should be an expert in pedagogy in order to develop innovative and creative teaching-learning practices. Fliers are made both for the list of all workshops offered during a given term and for each individual workshop. These are also announced over the campus's radio station. The following are the titles of the Viernes Didácticos offered during the spring semester of 2001.

1) Managing Stress in the Teaching-Learning Scenario 
2) Rubrics: An Instrument that Contributes Classroom Assessment and Evaluation

3) Collaborative Work

4) Conceptual Maps: An Instrument that Assists Our Teaching and Evaluation Practices

5) From the Real Classroom to the Virtual Classroom: Experiences in Distance Education

6) Constructivist Teaching Strategies

7) Intellectual Property and Copyright in Cyberspace

8) The Use of Etnography for Qualitative Analysis

Attendance in these workshops increased dramatically after we hired our secretary, who has taken care of all promotion efforts. Nonetheless, we have begun to observe a drop in attendance, which may well be a sign of fatigue. Although we have never allowed ourselves to be discouraged by relatively low attendance-after all, ten professors can represent as many as 800 students-we are currently exploring ways of responding to this drop. One possibility is to dedicate a whole semester to workshops specifically addressed to department chairs or to advisors, thus giving teaching faculty a respite from their Friday rendezvous with our center.

Another strategy deployed by the center is the appointment of resident professors in the areas of action research, technology, vernacular linguistic competencies, linguistic competencies in English, and quantitative reasoning skills. In order to make these appointments carry with them a prestige that would compensate for the low pay, we made sure to seduce widely respected faculty to serve as our first resident professors. These faculty offer the center nine hours per week or one fourth of their regular load. They schedule this time of availability in different ways so that they are able to consult with individual professors, offer workshops for specific groups or departments, and produce written materials to circulate on campus.

Through a grant from the W. K. Kellogg Foundation, we have also been able to offer several institutes: Summer Institute on Classroom Research, Fall Institute on the Development of Vernacular Linguistic Competencies Across the Curriculum, Spring Institute on the Development of Quantitative Competencies Across the Curriculum. These institutes are widely promoted and interested faculty are invited to apply, engaging 
themselves to pursue a specific project if their application is accepted and demonstrating departmental support. In the case of the summer institute, because it is held during a time when faculty are not required to come to campus, we offer a small stipend to participants.

As a result of our first Summer Institute on Classroom Research, the Río Piedras Campus held, on April 27, 2000, its first Classroom Research Conference in which the professors who participated in the institute, along with other invited faculty, presented their research projects.

In the area of technology, we offered our first Technology and Education Fair on May 2, 2000. For this activity, we made a call for proposals to faculty interested in presenting the ways in which they have incorporated technology into their teaching-learning practice. No use of technology was considered too small or insignificant as far as we were concerned. Should we have limited our fair to grandiose ventures into the use of technology, the results could well have been counterproductive, since many could easily have despaired of ever being able to do anything remotely similar. Two forums were held during the fair on matters related to the use of technology in the teaching-learning process. Software and hardware providers sponsored the fair through cash or in-kind donations.

Since 1990, the deanship for academic affairs has run a computer laboratory for faculty. Although efforts had been made to offer faculty upto-date technology through this lab, the truth is that academic affairs is ill-suited to run this type of operation. Thus, we persuaded the dean to transfer jurisdiction over to the center, which is better able to oversee the lab's operations and to provide it with a clearer sense of direction and purpose. Since the transfer was made effective, we have been able to present the chancellor with a proposal for the complete renovation of the lab. As of this writing, all signs are good that we will soon be able to purchase state-of-the-art hardware and software that will turn the laboratory into a truly effective tool for promoting the use of technology in the educational process.

Sustaining these efforts financially is an ongoing challenge. Our institutional budget is about one half of what we actually need to run the activities described above. Thus, we are constantly looking into ways of raising the funds necessary for the center's work. Apart from writing proposals to foundations, we submitted a proposal to our own campus under a program known as Intramural Practice. This program allows departments and individual faculty to develop for-profit activities using institutional facilities. Our proposal has been approved and will allow us to 
sell both summer institutes and weekend workshops outside the Rio Piedras Campus.

\section{MOVIng Forward}

Since its inception in 1998, our Center for Academic Excellence has become a noteworthy and respected presence on campus. In a report on a visit to Río Piedras, as part of our participation in the ACE/Kellogg Project, Dr. Madeleine Green, Vice President of the American Council on Education, wrote:

The creation of the Center for Academic Excellence ... has been key; it is not merely a center with a bunch of programs, but also a space that gives legitimacy to the dialogue about teaching and learning as well as a real set of activities... Several hundred faculty members have attended workshops during the "Didactic Fridays." There is clearly a demand for the Center's services. It is now a line item in the budget, which is important recognition by the Campus administration. There is widespread positive feeling about the Center, and some readiness to push the activities down into the schools and departments. It is a good sign that UPR is almost ready for the "next generation" of the Center. (M. Green, personal communication, March 9, 2000)

What does the next generation of the center look like from our vantage point? There is much work ahead of us if we are to take the Center for Academic Excellence in the direction of the vision contained in the proposal for its creation. Very little has been accomplished in the area of assessment, although we have heeded Portland's advice to develop a culture of evidence: We try to keep track of everything we do and make sure that it is evaluated. Anyone who ventures into our offices and asks what we are about will find evidence of our work and reports of our evaluations on a table in the reception area. Nonetheless, we are committed to developing the assessment area in the direction of formal assessment of learning.

Furthermore, we have not been able to do anything in the area of service-learning, which will become crucial once the academic senate approves a new curriculum. All of the proposals before the senate include the concept of a capstone seminar preferably based on service-learning.

But the task ahead of us is more complicated than just leading the 
center in the direction of its original vision. Recent work by the task forces involved in the ACE/Kellogg Project suggests that the Center for Academic Excellence should grow in the direction of incorporating academic support to students. The belief is that in a truly learning-centered institution it would be ill-advised to split the teaching-learning equation. If we are to promote academic excellence around the notion of the community of learners, then the center should model a new teaching-learning paradigm, one that conceptualizes teaching and learning as distinct but inextricable pieces in a heuristic process that leads to curricular innovation and, in turn, to new ways of approaching the institution's commitment to learning. Figure 5.1 attempts to express this new vision of the center.

FIGURE 5.1

\section{Center for Academic Excellence (Community of Learners)}

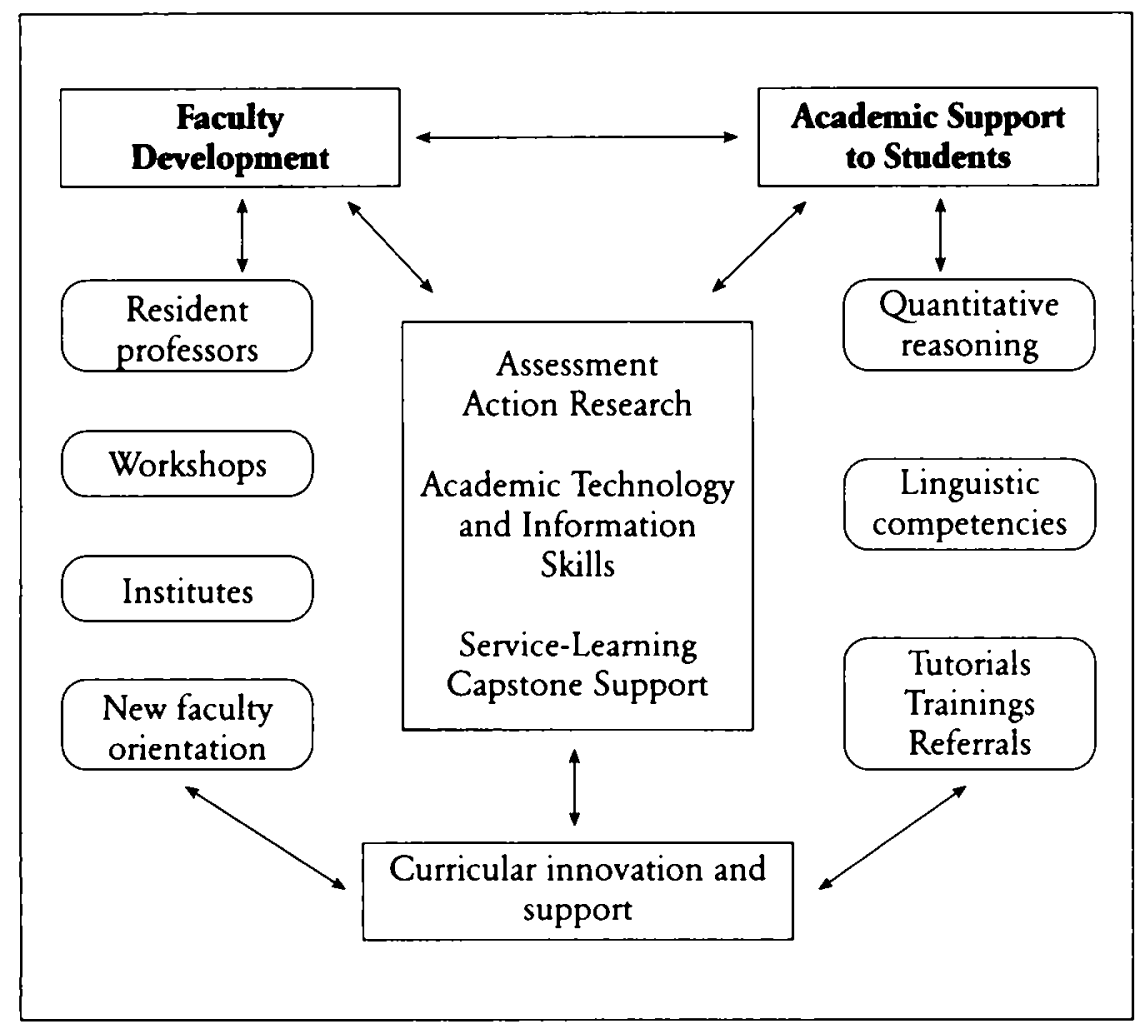


The center would have two major components: faculty development and academic support to students. Each of these components would develop its own activities addressed to its specific constituencies. The areas of assessment and action research, academic technology and information skills, and service-learning and capstone support, however, would serve both of the major components and would also develop activities and programs that bring together the teaching and learning aspects of the center's work.

We have taken our first small steps in the direction of this new vision. During the spring semester of 2000 , we began to survey the campus in search of academic support initiatives. This effort allowed us to identify three types of initiatives: programs addressed to specific groups (mostly TRIO programs), centers (such as computer or writing centers), and initiatives developed by individual professors. All of the people identified were invited to attend a meeting held in January 2001, in which our plans were presented and discussed, stressing our role as supportive of the efforts already underway. A call for proposals was made for our first Academic Support Initiatives Fair, to be held on April 19, 2001. Also, we have appointed a part-time academic support coordinator and resident professors in linguistic competencies in English and in quantitative reasoning skills.

It is our hope that by the university's first centennial in 2003, our campus will already have a Center for Academic Excellence that brings faculty and students together, in new ways, around the compelling challenge of learning.

\section{REFERENCES}

Barr, R. B., \& Tagg, J. (1995, November/December). From teaching to learning: A new paradigm for undergraduate education. Change, 13-25.

Bonwell, C. C., \& Eison, J. A. (1991). Active learming: Creating excitement in the classroom. San Francisco, CA: Jossey-Bass.

Boyer, E. (1990). Scholarship reconsidered: Priorities of the professoriate. Princeton, $\mathrm{NJ}$ : Carnegie Foundation for the Advancement of Teaching.

Brinko, K. T., \& Menges, R. J. (1997). Practically speaking: A sourcebook for instructional consultants in higher education.

Stillwater, OK: New Forums Press/Professional and Organizational Development Network in Higher Education. 
Farmer, D. W., \& Mech, T. F. (1992). Information literacy: Developing students as independent learners. New Directions for Higher Education, No. 78. San Francisco, CA: Jossey-Bass.

Gabelnick, F., MacGregor, J., Matthews, R., \& Smith, B. L. (1990). Learning communities: Creating connections among students, faculty, and disciplines. New Directions for Teaching and Learning, No. 41. San Francisco, CA: JosseyBass.

Grunert, J. (1997). The course syllabus: A learning-centered approach. Bolton, MA: Anker.

Meyers, C., \& Jones, T. (1993). Promoting active learning: Strategies for the college classroom. San Francisco, CA: Jossey-Bass.

Silberman, M. (1996). Active learning: 101 strategies to teach any subject. Boston, MA: Allyn and Bacon.

Sutherland, T. E., \& Bonwell, C. (1996). Using active learning in college classes: A range of options for faculty. New Directions for Teaching and Leaming, No. 67. San Francisco, CA: Jossey-Bass.

Wadsworth, E. C. (Ed.). (1988). A handbook for new practitioners. Stillwater, OK: New Forums Press/Professional and Organizational Development Network in Higher Education.

\section{END NoTes}

1. The Rio Piedras Campus, a Doctoral II institution according to Carnegie Foundation criteria, is the oldest and largest unit $(20,000$ students and 1,200 faculty) of the University of Puerto Rico 11-campus system. The Río Piedras Campus will celebrate its centennial in 2003.

2. In October 1999, the academic senate's Special Committee for the Reconceptualization of the Baccalaureate rendered its final report, tithed Project: A New Baccalaureate for the Year 2000. This report, along with an alternative proposal presented by the College of General Studies, were presented to, and discussed by, all of the colleges and other sectors of the academic community. The academic senate began to discuss the proposals during the spring semester of 2000 . As of this writing, the section on the new curricular structure has been approved and most of the implementation design has been agreed upon. It is expected that the Rio Piedras Campus will have approved 
a new, more flexible, baccalaureate curriculum by the end of the spring semester 2001. Regardless of these decisions, however, it has become clear that the process of institutional change spurred by the academic senate's decision concerns much more than curricula: It has moved the campus in the direction of a learning-centered institution.

\section{Contact:}

Nadia Cordero de Figueroa

Center for Academic Excellence

P. O. Box 23344

San Juan, PR 00931-233444

(787) $764-0000, x 2964$

(787) 772-1429 (Fax)

Email: ncordero@goliath.cnnet.clu.edu

Pedro A. Sandín-Fremaint

Center for Academic Excellence

P. O. Box 23344

San Juan, PR 00931-233444

(787) $764-0000, x 2964$

(787) 772-1429 (Fax)

Email: psandin@coqui.net

Nadia Cordero de Figueroa is Professor of Chemistry in the College of Natural Science at the Rio Piedras Campus of the University of Puerto Rico. She has been involved in teaching-learning research since the early 1970 s when she developed the PSI mode of instruction for the general chemistry course. She has been Associate Dean for Academic Affairs of the College of Natural Science (six years) and Acting Dean (three years). In 1999, the Carnegie Foundation recognized Professor Cordero as Professor of the Year in Puerto Rico.

Pedro A. Sandin-Fremaint is Professor of French in the Humanities College at the Rio Piedras Campus of the University of Puerto Rico, where he has served as Associate Dean for Academic Affairs. He chaired the Río Piedras' ACE/Kellogg Project on Leadership and Institutional Transformation, which supported institutional change efforts around the reconceptualization of the baccalaureate. He has been Associate Dean for Academic Affairs of the Río Piedras Campus.

Professors Figueroa and Sandin-Fremaint are cocreators and codirectors of the Rio Piedras Campus's Center for Academic Excellence. 